\title{
Occupational asthma due to tea dust
}

\author{
André Cartier, Jean-Luc Malo
}

\begin{abstract}
Three patients are described who had developed asthma after working as tea packers. In two cases the diagnosis was confirmed by serial monitoring of peak expiratory flow rates, bronchial responsiveness to histamine, and specific inhalation challenges in the laboratory. The third patient experienced isolated changes in bronchial responsiveness to histamine after periods of exposure at work and after specific inhalation challenges in the laboratory without showing spirometric changes. Two of the three subjects were non-atopic; none had an immediate reaction to skin prick testing with a tea solution.
\end{abstract}

Occupational asthma among workers processing different plants, grains, and beans has been frequently documented. ${ }^{12}$ Occupational asthma due to tea fluff, a dust released during the processing of tea leaves, has been described ${ }^{3}$ and asthma due to tea dust has been documented in a tea packer. ${ }^{4}$ We describe three patients who developed occupational asthma as a reaction to téa dust while working in a plant where tea dust was packed into tea bags.

\section{Case reports}

Baseline data for all the patients are given in the table. Histamine challenge tests were carried out as described elsewhere. ${ }^{56}$

\section{SUBJECT 1}

This 43 year old woman had been symptom free until nine months before her first visit to the clinic, at which time she had noticed rhinorrhoea, cough, dyspnoea, and wheezing. The symptoms were more pronounced at work, and she woke during the night with chest symptoms when she had been at work. Her symptoms improved with oral theophylline, an inhaled beta ${ }_{2}$ adrenergic agent, and beclomethasone, and they cleared after one month away from work, so that she was able to stop all medication. On her return to work her asthma and rhinitis recurred within two weeks. She was again removed from the workplace for one month, and given a short course of oral prednisone. When she returned to work, taking oral theophylline and inhaled beclomethasone (200 $\mu \mathrm{g}$ daily), symptoms recurred again and were controlled by inhaled salbutamol as needed. She was symptom free when first seen by us, having been away from work for three weeks. Spirometry gave normal results. ${ }^{7}$ The variability in her peak flow meter values recorded every two waking hours was less than $20^{\circ}$ o (fig 1). Two histamine inhalation tests showed borderline hyperresponsiveness.

Returning to work caused a recurrence of her symptoms, increased fluctuation in her peak expiratory flow (PEF) and a fall in her $\mathrm{PC}_{20}$ (the provocation concentration of histamine causing a $20^{\circ}{ }_{o}$ fall in $\mathrm{FEV}_{1}$ ) and $\mathrm{FEV}_{1}$ (fig 1). Removal from the workplace caused an improvement in PEF, $\mathrm{FEV}_{1}$, and symptoms without any extra medication; the patient was completely symptom free after six weeks away from work. The $F E V_{1}$ returned to normal but her $\mathrm{PC}_{20}$ histamine was still low more than a month after she left work.

To determine whether tea dust was responsible for the exacerbation of asthma at work, specific inhalation challenges were performed (fig 2). Exposure to wood dust for two hours, ${ }^{8}$ as a control, induced no change in spirometric values. $P_{20}$ was $1.6 \mathrm{mg} / \mathrm{ml}$ at the end of the day. The next day, gradual exposure to tea dust for a total of 30 minutes induced an atypical early late asthmatic reaction, beginning 20 minutes after the last exposure and producing a maximum fall in $\mathrm{FEV}_{1}$ of $29 \%$ from baseline three hours after exposure ended. $\mathrm{PC}_{20}$ on the following day was decreased slightly to 0.69 $\mathrm{mg} / \mathrm{ml}\left(\mathrm{FEV}_{1}\right.$ within $10 \%$ of the baseline value of the first histamine test).

\section{SUBJECT 2}

This 38 year old woman, a machine operator, reported perennial rhinitis of seven years' duration, associated with cough, shortness of breath, and wheezing over the previous four years. The symptoms increased three hours after arriving at work and caused her to awaken
Coeur, Hôpital du

H4J 1 C5.

Accepted 13 November 1989

\begin{tabular}{|c|c|c|c|c|c|c|c|c|c|c|}
\hline $\begin{array}{l}\text { Patient } \\
\text { No }\end{array}$ & Age (y) & Atopy & $\begin{array}{l}\text { Skinprick } \\
\text { reaction to } \\
\text { tea dust }\end{array}$ & $\begin{array}{l}\text { Smoking } \\
\text { habit }\end{array}$ & $\begin{array}{l}\text { Duration of } \\
\text { exposure }(y)\end{array}$ & $\begin{array}{l}\text { Duration of } \\
\text { symptoms }(y)\end{array}$ & $\begin{array}{l}F E V, \\
\text { (\% pred) }\end{array}$ & $\begin{array}{l}F E V_{1} / F V C \\
\text { (\% pred) }\end{array}$ & $\begin{array}{l}P C_{20} \\
(\mathrm{mg} / \mathrm{ml})\end{array}$ & $\begin{array}{l}\text { Specific IgE } \\
\text { to tea dust } \\
\text { (cpm })^{\star}\end{array}$ \\
\hline $\begin{array}{l}1 \\
2 \\
3\end{array}$ & $\begin{array}{l}43 \\
38 \\
40\end{array}$ & $\begin{array}{l}\overline{-} \\
+\end{array}$ & $\begin{array}{l}- \\
-\end{array}$ & $\begin{array}{l}\text { Ex-smoker } \\
\text { Ex-smoker } \\
\text { Non-smoker }\end{array}$ & $\begin{array}{l}27 \\
19 \\
19\end{array}$ & $\begin{array}{r}<1 \\
4 \\
<1\end{array}$ & $\begin{array}{l}83 \\
91 \\
95\end{array}$ & $\begin{array}{r}100 \\
87 \\
103\end{array}$ & $\begin{array}{r}12.5 \\
5.9 \\
7.4\end{array}$ & $\begin{array}{l}\text { ND } \\
362 \\
392\end{array}$ \\
\hline
\end{tabular}

^Mean value of $382 \mathrm{cpm}$ in three non-atopic, non-asthmatic individuals. ND-not done. 


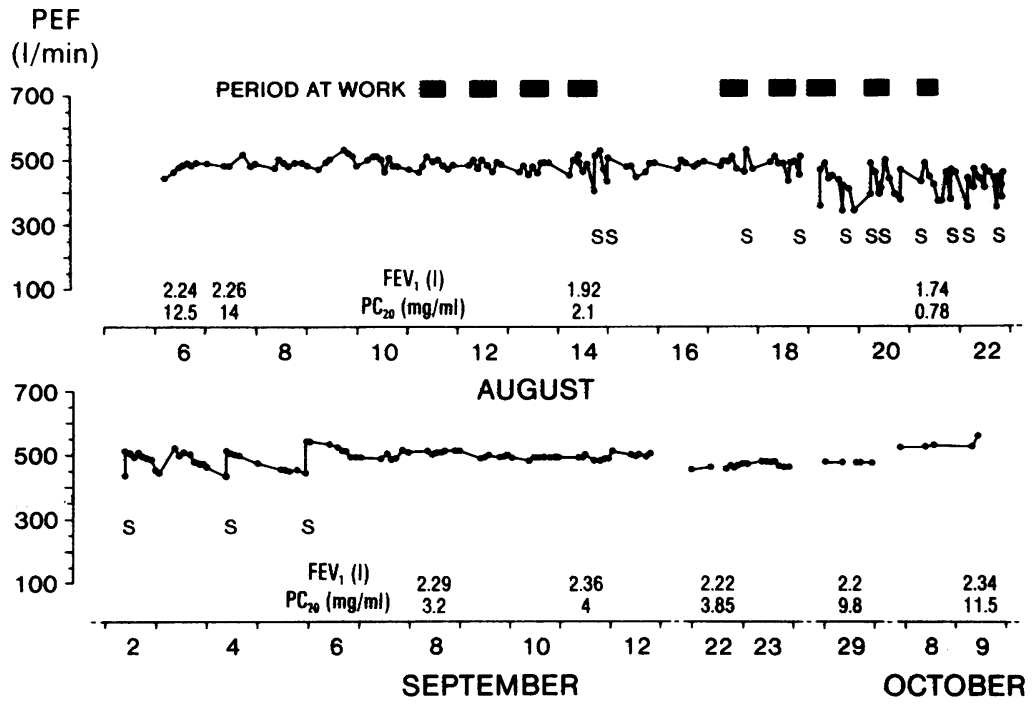

Figure 1 Combined monitoring of peak expiratory flow (PEF) and responsiveness to histamine $\left(P C_{20}\right)$ in subject 1 . Significant changes in PEF were documented in the second week of exposure, coinciding with a need for an inhaled beta $a_{2}$ adrenergic agent $(S)$. FEV , values at the time of $P C_{20}$ assessment are given.

occasionally at night. They improved during weekends and holidays. She was treated with oxtriphylline and an inhaled beta ${ }_{2}$ adrenergic agent. The diagnosis of asthma was confirmed two years after the start of symptoms, when spirometry showed partially reversible airway obstruction with an $\mathrm{FEV}_{1}$ and forced vital capacity (FVC) of 1.35 and 2.021 , improving to 1.74 and 2.681 after inhaled beta adrenergic agent (predicted values 2.51 and 2.941 ). Her chest symptoms steadily worsened over several years, so she left her job one year before being seen. She was completely symptom free after several months away from work. She underwent specific inhalation challenges as for subject 1 . Neither exposure to tea dust for 60 minutes as described above nor inhalation of a

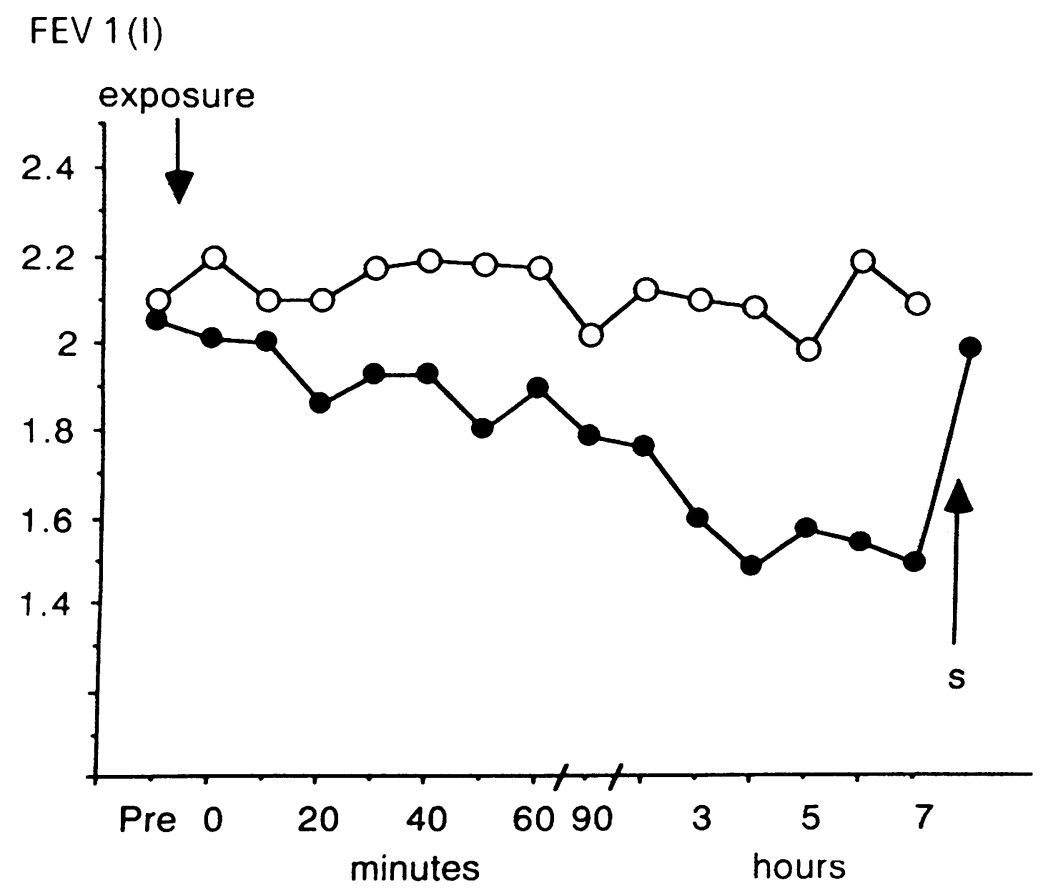

Figure 2 Results of specific inhalation challenges with wood dust (two hours, $\bigcirc$ ) and tea dust (30 minutes, ) in subject 1 . S-inhalation of a beta ${ }_{2}$ adrenergic agent. Specific inhalation challenges were performed during 22 August-2 September. tea dust solution for five and 30 minutes via a Wright nebuliser (output $0.14 \mathrm{ml} / \mathrm{min}$ ) on three consecutive days induced a change in $\mathrm{FEV}_{1}$ of $8 \%$ or more over eight hours (fig 3), though she developed cough and shortness of breath. Her $\mathrm{PC}_{20}$ fell on each occasion; at this time the maximum variability in baseline $\mathrm{FEV}_{1}$ was $10.9 \%$. The diagnosis was not retained because $F E V_{1}$ did not change after the challenge test; no explanation was found for the changes in bronchial responsiveness.

Two years later, after a diagnosis of occupational asthma had been confirmed in another worker from the same processing plant (No 3 below), we decided to repeat the tea dust exposure tests at work and in the laboratory for longer periods. The subject was still symptom free and had no bronchial hyperresponsiveness. Returning to work caused her to cough but was not associated with any appreciable changes in peak expiratory flow (PEF). Her $\mathrm{PC}_{20}$ fell after two periods of five days at work (fig 3), but had risen to over $32 \mathrm{mg} / \mathrm{ml}$ one week later. Specific inhalation challenges were then repeated in the laboratory. Baseline $\mathrm{PC}_{20}$ was over $16 \mathrm{mg} / \mathrm{ml}$. Exposure to tea dust for four hours resulted in a fall in $\mathrm{PC}_{20}$ from over 32 to $3.8 \mathrm{mg} / \mathrm{ml}$, with progressive recovery over the next six days. The maximum variability in $\mathrm{FEV}_{1}$ during the day was $7 \cdot 1 \%$. After exposure to wood dust for four hours the maximum variability in $\mathrm{FEV}_{1}$ was $8.6 \%$ and $\mathrm{PC}_{20}$ was over $16 \mathrm{mg} / \mathrm{ml}$. Repeat exposure to tea dust for four hours did not result in any change of note in $\mathrm{FEV}_{1}$ (maximum daily variability $4.3 \%$ ). There was also no change in lung volumes (residual volume, functional residual capacity, total lung capacity) or maximum flow at $50 \%$ of forced vital capacity. There was, however, a fall in $\mathrm{PC}_{20}$, with progressive recovery over the next few days at a time when the maximum variability in baseline $\mathrm{FEV}_{1}$ before each histamine test was $10.6 \%$ (fig 3 ). The subject had cough and shortness of breath at the time of exposure to tea dust but not with wood dust.

An asthmatic subject with a $\mathrm{PC}_{20}$ of 1.4 $\mathrm{mg} / \mathrm{ml}$ was exposed to tea dust for two hours in the laboratory as a control; the exposure, which was similar to the one for the other subjects, did not induce any changes in $\mathrm{FEV}_{1}(<10 \%)$ or in $\mathrm{PC}_{20}(2 \cdot 1 \mathrm{mg} / \mathrm{ml}$ at the end of the day).

SUBJECT 3

This 40 year old woman reported cough with chest tightness and wheezing that was more pronounced in the afternoon when she was at work. She also reported waking at night with asthmatic symptoms. There was improvement during weekends and holidays. She was atopic (positive skinprick test responses to ragweed pollen and Dermatophagoides farinae) but reported no history of hay fever. The $\mathrm{PC}_{20}$ was $7.4 \mathrm{mg} / \mathrm{ml}$ (baseline $\mathrm{FEV}_{1} 2.74 \mathrm{l}$ ) after two months away from work. After returning to work for two weeks her $\mathrm{PC}_{20}$ had fallen to 1.5 $\mathrm{mg} / \mathrm{ml}$ (baseline FEV $2.56 \mathrm{l}$ ). PEF monitoring showed greater fluctuations when she was at work than during a weekend and a period before exposure at work (fig 4). Specific inhala- 


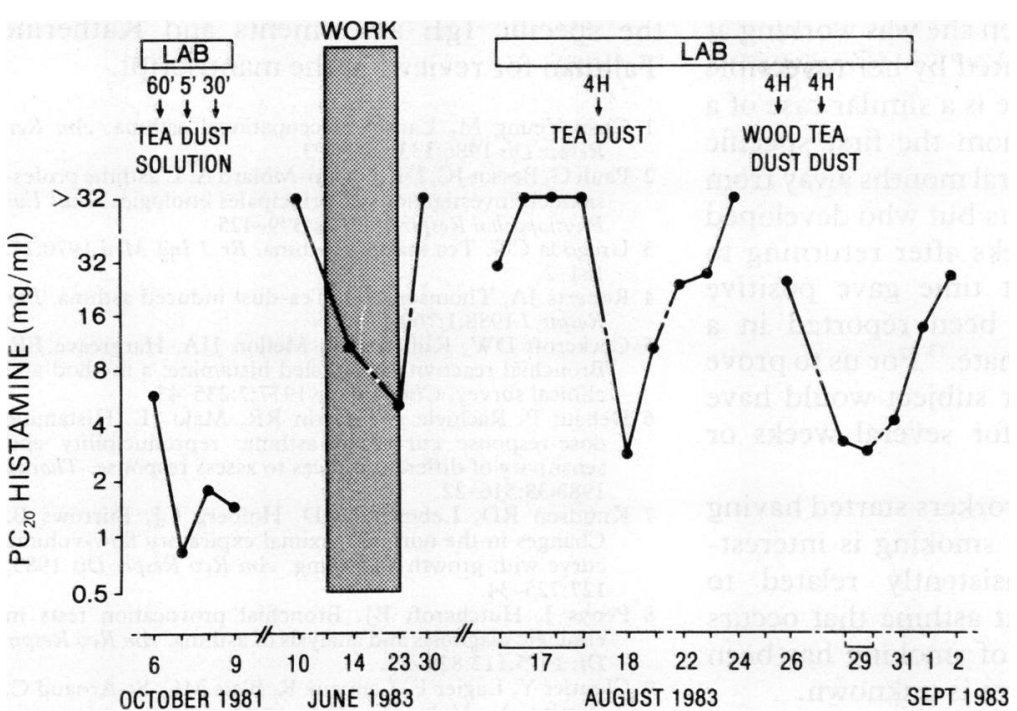

Figure 3 Results of specific inhalation challenges in subject 2. No significant changes in $F E V$, were documented. The duration of exposure to each agent at work and in the laboratory is shown.

tion challenges were performed by asking the subject to tip tea dust. Exposure to wood dust for two hours resulted in a maximum fall in $\mathrm{FEV}_{1}$ of $11.8 \%$ two hours after the end of exposure. Exposure to tea dusts for two hours on two different occasions caused maximum falls in $\mathrm{FEV}_{1}$ of $38 \%$ and $40 \%$ two hours and four hours after the end of exposure. On the second occasion exposure induced an earlier change in $\mathrm{FEV}_{1}$, and the subject required inhaled salbutamol (fig 5). PC $_{20}$ was essentially unchanged after the tests $\left(\mathrm{PC}_{20}\right.$ values of $1 \cdot 1$ and $1.4 \mathrm{mg} / \mathrm{ml}$ before and after).

\section{Discussion}

Two cases of occupational asthma due to tea dust have been already documented. ${ }^{34} \mathrm{Al}$ though in the first case the worker was employed in the primary industry, ${ }^{3}$ in the second case the worker was a tea packer like our

PEF

$(1 / \mathrm{min})$

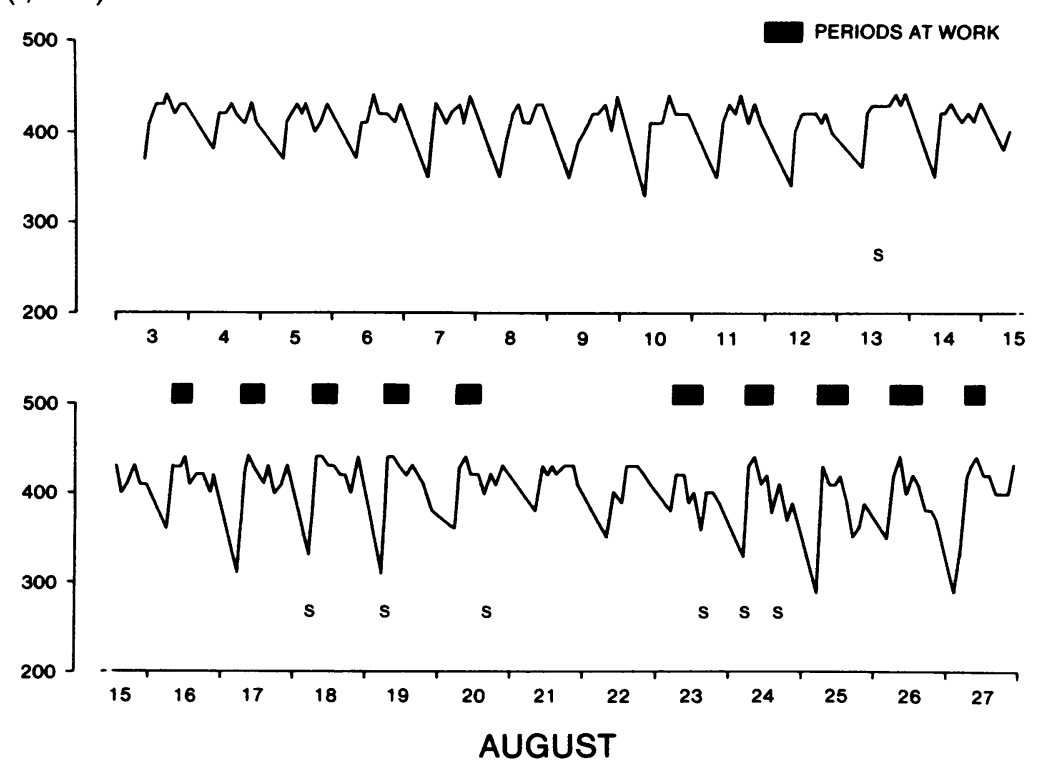

Figure 4 Monitoring of peak expiratory flow (PEF) at work and away from work in subject 3. S-inhalation of a beta $a_{2}$ adrenergic agent. subjects. In the second case ${ }^{4}$ the diagnosis was confirmed by serial monitoring of PEF and specific inhalation challenges, whereas in the first case the diagnosis was a clinical one. ${ }^{3}$ In our two workers the diagnosis of occupational asthma was confirmed by monitoring peak expiratory flow. As this does not exclude the possibility of an irritant reaction, we combined monitoring with serial assessment of bronchial responsiveness. Substantial changes in $\mathrm{PC}_{20}$ were documented in both subjects and were prolonged in the first subject. Finally, specific inhalation challenges confirmed the diagnosis of occupational asthma as they induced a late reaction in one subject and an atypical immediate or early late reaction in the other. Although the exposure level at the time of specific inhalation challenges was not monitored and could have been high at this time, ${ }^{9}$ this pattern of reaction excludes a non-specific irritant mechanism; asthmatic subjects exposed to high levels of particles such as sawdust do not generally show changes in spirometric values and bronchial responsiveness after exposure. ${ }^{10}$ Furthermore, a control asthmatic subject showed no changes in $\mathrm{FEV}_{1}$ or $\mathrm{PC}_{20}$ after a similar exposure to tea.

The second subject illustrates an interesting point. Although exposure to tea dust caused little change in $\mathrm{FEV}_{1}$ or PEF, there was a change in $\mathrm{PC}_{20}$ of up to four doubling doses, from normal to within the asthmatic range. Such changes cannot be attributed to an irritant reaction; the subject did not show bronchial hyperresponsiveness at the start of the challenges on three separate occasions and recovery of $\mathrm{PC}_{20}$ took several days. Finally, changes in $\mathrm{PC}_{20}$ were not documented in a control subject who had bronchial hyperresponsiveness. The effect of exposure to an environmental asthma inducing agent may at times be detected more readily from change in bronchial responsiveness than from changes in FEV or FVC." ${ }^{11}$ The lack of changes in $\mathrm{FEV}_{1}$ and/or FVC after exposure to tea dust might be due to the fact that the subject had been away from work for a long interval when the tests were carried out. She is likely to have lost some sensitisation. It is difficult to label this case occupational asthma, though she

FEV,

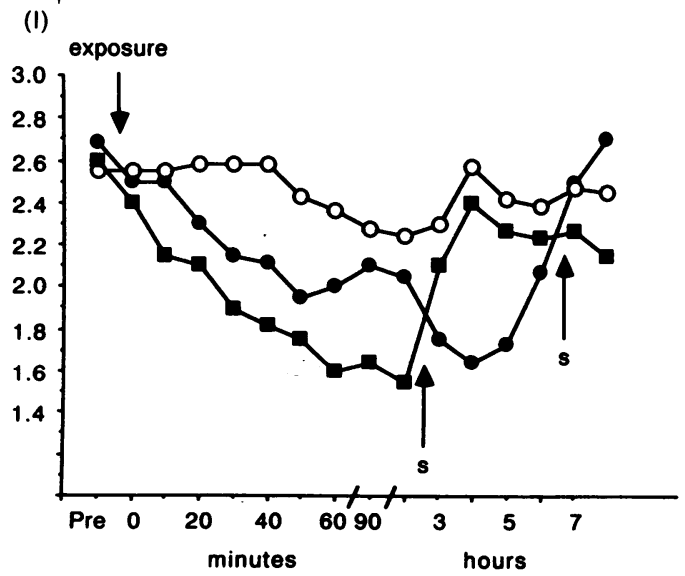

Figure 5 Results of specific inhalation challenges with wood dust $(O)$ and tea dust ( first exposure, second exposure) in subject $3 . S$-inhalation of a beta adrenergic agent. 
definitely had asthma when she was working at the tea plant, as documented by her reversible airway obstruction. There is a similar case of a snow crab worker in whom the first specific challenge, done after several months away from work, gave negative results but who developed asthma again several weeks after returning to work; challenges at that time gave positive results. ${ }^{12}$ This has also been reported in a worker exposed to isocyanate. ${ }^{13}$ For us to prove the point definitively our subject would have had to return to work for several weeks or months.

That two of the three workers started having symptoms after stopping smoking is interesting. Smoking is inconsistently related to occupational asthma, ${ }^{1}$ but asthma that occurs or recurs after cessation of smoking has been described ${ }^{14}$; the mechanism is unknown.

The mechanism of this type of occupational asthma is not understood. We and others ${ }^{4}$ were unable to detect specific $\mathrm{IgE}$, and skin tests failed to elicit an immediate reaction. The causative agent could be the tea plant itself or a microbial contaminant, though immediate skin reactions were found in the patient in the original report. ${ }^{3}$ The prevalence of occupational asthma among workers exposed to tea dust remains to be explored.

We would like to thank Dr Jerry Dolovich, Department of Pediatrics, McMaster University, Hamilton, for kindly agreeing to perform the specific IgE assessments and Katherine Tallman for reviewing the manuscript.

1 Chan-Yeung M, Lam S. Occupational asthma. Am Rev Respir Dis 1986;133:686-703.

2 Pauli G, Bessot JC, Dietemann-Molard A. L'asthme professionnel: investigations et principales étiologies. Bull Eur Physiopathol Respir 1986:22:399-425.

3 Uragoda CG. Tea maker's asthma. Br J Ind Med 1970;27: 181-2.

4 Roberts JA, Thomson NC. Tea-dust induced asthma. Eur Respir J 1988;1:769-70.

5 Cockcroft DW, Killian DN, Mellon JJA, Hargreave FE Bronchial reactivity to inhaled histamine: a method and clinical survey. Clin Allergy 1977;7:235-43

6 Dehaut P, Rachiele A, Martin RR, Malo JL. Histamin dose-response curves in asthma: reproducibility and sensitivity of different indices to assess response. Thorax 1983;38:516-22.

7 Knudson RD, Lebowitz MD, Holberg CJ, Burrows B. Changes in the normal maximal expiratory flow-volume curve with growth and aging. Am Rev Respir Dis 1983; 127:725-34.

8 Pepys J, Hutchcroft BJ. Bronchial provocation tests in etiologic diagnosis and analysis of asthma. Am Rev Respir Dis 1975;112:829-59.

9 Cloutier Y, Lagier F, Lemieux R, Blais MC, St-Arnaud C, Cartier A, Malo JL. New methodology for specific inhalation challenges with occupational agents in powde form. Eur Respir J 1989;2:769-77.

10 De Luca S, Caire N, Cloutier Y, Cartier A, Ghezzo H, Malo $\mathrm{JL}$. Acute exposure to sawdust does not alter airwa caliber and responsiveness to histamine in asthmatic subjects. Eur Respir J 1988;1:540-6.

11 Cartier A, L'Archevêque J, Malo JL. Exposure to a sensitizing agent can cause a long-lasting increase in bronchial responsiveness to histamine in the absence of significant changes in airway caliber. J Allergy Clin Immunol 1986;78. 1185-9.

12 Cartier A, Malo JL, Forest $F$, Lafrance $M$, Pineau $L$, St-Aubin JJ, Dubois JY. Occupational asthma in snowSt-Aubin JJ, Dubois JY. Occupational asthma in snowcrab proc.

13 Butcher BT, O'Neil CE, Reed MA, Salvaggio JE, Weill H. Development and loss of toluene diisocyanate reactivity: immunologic, pharmacologic, and provocative challenge studies. J Allergy Clin Immunol 1982;70:231-5.

14 Hillerdahl G, Rylander R. Asthma and cessation of smoking. Clin Allergy 1984;14:45-7. 